\title{
Primary spontaneous pneumothorax: a cohort study of VATS with talc poudrage
}

\author{
Giuseppe Cardillo, ${ }^{1}$ Oliver J Bintcliffe, ${ }^{2}$ Francesco Carleo, ${ }^{1}$ Luigi Carbone, ${ }^{1}$ \\ Marco Di Martino, ${ }^{1}$ Brennan C Kahan, ${ }^{3}$ Nick A Maskell ${ }^{2}$
}

${ }^{1}$ Unit of Thoracic Surgery, L.

Spallanzani Hospital, Azienda Ospedaliera San Camillo Forlanini, Rome, Italy ${ }^{2}$ Academic Respiratory Unit, School of Clinical Sciences, University of Bristol, Bristol, UK ${ }^{3}$ Pragmatic Clinical Trials Unit, Queen Mary University of London, London, UK

\section{Correspondence to}

Prof Nicholas A Maskell, Academic Respiratory Unit, School of Clinical Sciences, University of Bristol, Bristol BS10 5NB, UK;

Nick.Maskell@bristol.ac.uk

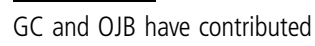
equally.

Received 26 October 2015 Revised 2 February 2016 Accepted 5 February 2016 Published Online First 15 July 2016

\begin{abstract}
Background Video-assisted thoracoscopic surgery

(VATS) is an increasingly common treatment for recurrent or persistent primary spontaneous pneumothorax (PSP). Surgery usually involves diffuse treatment of the pleura and possible targeted therapy to areas of bullous disease. The purpose of this large cohort study was to examine incidence of recurrence after VATS and identify predictors of outcome.

Methods Patients undergoing VATS for PSP at a single centre between 2000 and 2012 were prospectively enrolled. All patients underwent talc poudrage. Targeted surgical techniques were used based on presence of air leak and Vanderschueren's stage. Patients had clinical and radiological follow-up for at least 2 years (median 8.5 years).
\end{abstract}

Results 1415 patients with PSP underwent VATS with talc poudrage. The most frequent indications were recurrent pneumothorax (92.2\%) and persistent air leak $(6.5 \%)$. The complication rate was $2.0 \%$ of which $1.7 \%$ was prolonged air leak. There was no mortality. Median length of stay was 5 days. Recurrent pneumothorax occurred in 26 patients (1.9\%). At the time of surgery, 592 patients smoked (43\%) and they had a significantly higher incidence of recurrence $(24 / 575,4.2 \%)$ than nonsmokers $(2 / 805,0.2 \%), p<0.001$. The incidence of recurrence in those undergoing bullae suturing $(3.8 \%$, $\mathrm{n}=260$ ) was significant higher than those undergoing poudrage alone $(0.3 \%, p=0.036)$.

Conclusion The marked difference in recurrence between smokers and non-smokers suggests this as an important predictor of outcome. This study demonstrates a low incidence of recurrence and complications for patients with PSP undergoing VATS with talc poudrage. Talc poudrage requires prospective comparison with pleurectomy and mechanical abrasion.

\section{INTRODUCTION}

Video-assisted thoracoscopic surgery (VATS) for pneumothorax is associated with a marked reduction in recurrence to around $3 \% .^{1}$ Without intervention, recurrence rates after primary spontaneous pneumothorax (PSP) are variably reported, with studies quoting rates as low as $26 \%$ and as high as $49 \%$ at 1 year. $^{2}{ }^{3}$ VATS is typically well tolerated, increasing in popularity and is the procedure of choice in many centres. ${ }^{4}$

A meta-analysis, combining randomised and nonrandomised studies has suggested that there is a higher recurrence rate associated with VATS compared with open thoracotomy. ${ }^{6}$ A systematic review,

\section{Key messages}

What is the key question?

- What is the incidence of recurrence for patients with primary spontaneous pneumothorax (PSP) undergoing video-assisted thoracoscopic surgery (VATS) with talc poudrage?

\section{What is the bottom line?}

- This is the largest prospectively collected surgical series of patients with PSP undergoing VATS showing a very low cumulative incidence of recurrence after VATS (1.9\%) and highlights smoking as a strong predictor of recurrence.

\section{Why read on?}

- This large surgical series of patients with PSP demonstrates an incidence of recurrent pneumothorax after VATS and talc poudrage lower than that previously reported in series using pleurectomy or mechanical abrasion.

however, including only randomised studies concluded that VATS was superior to thoracotomy in terms of pain relief, duration of hospital stay and atelectasis following the procedure. ${ }^{4}$ Much of the data suggesting a higher recurrence rate with VATS than with open thoracotomy were reported prior to 2000 and the demonstrated learning curve associated with VATS may be a reason for the initially poor results and explain why recent randomised studies have shown no difference in recurrence rates between VATS and an open approach. ${ }^{17}$

International management guidelines typically advocate thoracic surgical intervention for patients with non-resolving pneumothorax, a recurrent episode, haemothorax, bilateral pneumothoraces or for professions at risk, ${ }^{8}$ though in the future the indication for definitive treatment may expand to patients predicted to have a high risk of recurrence after an initial episode. ${ }^{9}$

A previous study of VATS for complicated or recurrent PSP $(n=432)$ demonstrated a lower rate of recurrence associated with talc poudrage compared with subtotal pleurectomy when used alone or alongside ligation or stapling of bullae $(1.8 \%$ vs $9.2 \%) .{ }^{10} \mathrm{~A}$ subsequent study of VATS with talc poudrage including 861 patients reported recurrence in $1.7 \% .^{11}$

The role of blebs and bullae in the aetiology of air leak in pneumothorax is not precisely 
understood. ${ }^{12}$ A study using fluorescein-enhanced autofluorescence thoracoscopy has suggested the presence of air leak in areas distinct from visually abnormal lung, in support of the concept of diffuse air leak causing pneumothorax. ${ }^{13}$ The evidence that pleurodesis alongside bullectomy reduces recurrence compared with bullectomy alone also points towards the need for diffuse treatment alongside more targeted therapy. ${ }^{14-16} \mathrm{~A}$ variety of surgical techniques have been used to treat bullous disease and there is a lack of evidence as to whether alternative strategies influence recurrence rates.

We have conducted a large, prospective cohort study of consecutive patients undergoing VATS and talc poudrage for PSP in order to better establish the long-term incidence of recurrence and complications associated with this procedure. We also aimed to establish variables affecting recurrence including patient factors and the nature of the surgical procedure, specifically regarding the intervention used to treat bullae.

\section{METHODS}

This study was a prospective observational cohort study of patients requiring VATS for PSP. All patients who underwent VATS at Carlo Forlanini Hospital, Rome, Italy, between January 2000 and December 2012 (inclusive) were invited to take part in the study. The research was approved by the hospital institutional review board and informed consent was obtained from each patient. Carlo Forlanini Hospital is one of six thoracic surgery units serving the region of Lazio, which has six million inhabitants.

Details of all patients included in the study were prospectively collected. Patients with known underlying lung disease or traumatic pneumothorax were excluded. Past medical history, smoking status and indication for surgery were recorded prospectively. Data missing at the time of enrolment were collected later during follow-up.

All operations were performed under general anaesthesia using a double-lumen endotracheal tube and single lung ventilation. A two-port or three-port technique was used and a $10 \mathrm{~mm}$ endoscope was used. The lung was carefully inspected for the presence of blebs or bullae (defined as subpleural, thin walled, air-filled spaces visible at thoracoscopy). In all patients the lung was examined during ventilation with saline in the pleural cavity to establish the presence of an air leak. Vanderschueren's stage was recorded (see table 1).

Talc poudrage was performed with nebulisation of $3-4 \mathrm{~g}$ of sterile graded talc (Steritalc). Talc poudrage was performed under direct visual control ensuring distribution of talc from the apex to the diaphragm.

Decisions on the intervention performed at VATS were made on the basis of the presence and size of blebs and bullae and the presence or absence of an air leak assessed by the water test (see figure 1). In some subgroups, the surgical procedure performed varied; this was based on differences in practice of individual surgeons.

Table 1 Vanderschueren's stage

\begin{tabular}{ll}
\hline Vanderschueren's stage & Thoracoscopic appearance \\
\hline Stage 1 & No endoscopic abnormalities \\
Stage 2 & Pleuropulmonary adhesions \\
Stage 3 & Blebs or bullae $<2 \mathrm{~cm}$ in greatest diameter \\
Stage 4 & Bullae $>2 \mathrm{~cm}$ in greatest diameter \\
\hline
\end{tabular}

For patients with no identified air leak and no evidence of bullae, talc poudrage was performed in isolation. In patients with no leak and Vanderschueren's stage 3 or stage 4, patients underwent talc poudrage alone, or they underwent talc poudrage alongside bullae resection or bulla suturing. Electrocoagulation was performed in a small number of selected patients with very small bullae $(<1 \mathrm{~cm})$ and no identified air leak.

In patients with an air leak and Vanderschueren's stages 1-3, bullae were sutured or resected. Patients with an air leak and Vanderschueren's stage 4 underwent resection, and for those with giant bullae in whom a lung-sparing procedure was not possible, lobectomy was performed.

Electrocoagulation involved treating small bulla at the visceral pleural surface with diathermy. Bullae suturing was achieved through the use of a no-knife stapler (Ethicon Endo-Surgery, Cincinnati, Ohio, USA) at the base of the bulla to avoid a leak. Bullae ligation was achieved with a 0 or 00 coated Vicryl Roeder loop (Ethicon, Somerville, New Jersey, USA) and was performed in small number of patients in view of concerns of frequent recurrence. Bullae resection was accomplished with an endostapler (Ethicon Endo-Surgery, Cincinnati, Ohio, USA). Surgical details including conversion to thoracotomy, pleurodesis technique, intervention to bulla and complications were recorded contemporaneously.

\section{Follow-up}

Chest radiographs were performed on all patients at 1, 3 and 6 months following surgery and annually for the following 5 years. In the event of a missed appointment, patients were contacted by telephone. All patients were also followed up by telephone in December 2014 to establish the incidence of recurrence. Patients lost to follow-up were censored at the point of last known follow-up and patients with no available follow-up data were excluded from analysis of recurrence.

\section{Statistical analysis}

The primary end point of the study was cumulative incidence of recurrent pneumothorax. Cumulative incidence is reported at 1 year and at 2 years. Secondary end points were surgical complications, duration of inpatient stay and chest drain removal by day 4. Drain removal by day 4 was selected as a longer dwell time than this was likely to lead to a delay in discharge. Persistent air leak was defined as a complication if it persisted for $>7$ days. We summarised outcomes both overall and according to the surgical intervention. We used $\chi^{2}$ tests to compare differences in complications and time of drain removal between different surgical interventions, and used the Kruskal-Wallis test to compare differences in length of stay between different surgical interventions. We then fitted a multivariable Cox regression model to assess the impact of patient factors (smoking status, gender, side and Vanderschueren's stage) and surgical procedures on time to recurrence. We also adjusted for date of surgery as a continuous variable. Patients lost to follow-up were censored at the time of last known follow-up and patients without a recurrence were censored at the end of the follow-up period. Patients with no available follow-up information were excluded. Statistical analyses were performed with STATA (V.13.1).

\section{RESULTS}

A total of 1415 patients underwent VATS over the 13-year study period. All patients had talc poudrage and five patients underwent partial pleurectomy in addition to talc poudrage. 
Figure 1 Flow diagram showing selection of thoracic surgical intervention based on surgical findings.

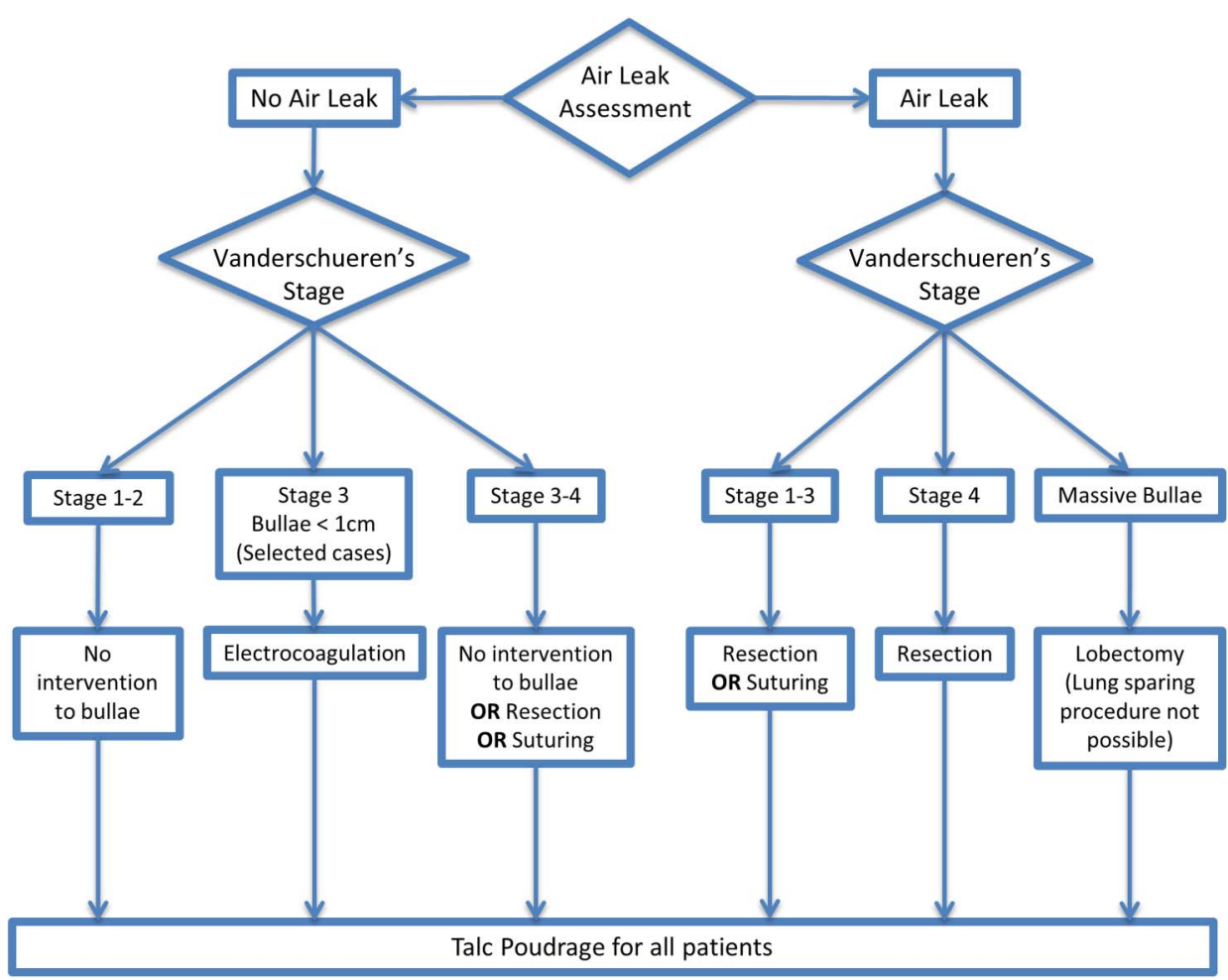

Thirty-five patients had no available follow-up data; recurrence data were therefore available for 1380 patients. Median follow-up was 8.5 years (IQR 4.9-11.9). All patients were followed up for a minimum of 2 years.

Characteristics of patients, surgical indications and the presence of bullae are shown in table 2. Two patients were

Table 2 Patient characteristics

\begin{tabular}{lc}
\hline Variable & Result \\
\hline Sex—n (\%) & \\
Male & $1078(76.2)$ \\
Female & $337(23.8)$ \\
Age (years)—median (IQR) & $25.3(21.0-29.4)$ \\
Side of pneumothorax—n (\%) & \\
Right & $842(59.5)$ \\
Left & $573(40.5)$ \\
Smoking history—n (\%) & \\
Never smoker & $810(57.2)$ \\
Current smoker & $592(41.8)$ \\
Ex-smoker & $13(0.9)$ \\
Vanderschueren's stage-n (\%) & \\
Stage 1 & $29(2.0)$ \\
Stage 2 & $383(27.1)$ \\
Stage 3 & $801(56.6)$ \\
Stage 4 & $202(14.3)$ \\
Surgical indication—n (\%) & \\
Recurrence & $1304(92.2)$ \\
Persistent air leak & $92(6.5)$ \\
Haemopneumothorax & $13(0.9)$ \\
First contralateral episode: & $4(0.3)$ \\
Bilateral pneumothorax & $1(0.01)$ \\
Profession at risk & $1(0.01)$ \\
\hline
\end{tabular}

converted from VATS to open thoracotomy. The number of surgical interventions used through the study period are provided in table 3 .

\section{Postoperative stay and complications}

Mean postoperative stay was 5.4 days (95\% CI 5.4 to 5.5 ) and ranged from 4 to 12 days. A total of 1282 patients (90.6\%) had their drains removed by the fourth postoperative day. Drains were removed from 92 patients $(6.5 \%)$ on day 5, from 29 patients $(2.0 \%)$ on day 6 and from 12 patients $(0.8 \%)$ after $\geq 7$ days.

Complications occurred in 29 patients (2.0\%). In the majority of cases $(n=24)$, this complication was a prolonged air leak (1.7\% of total); one patient had significant bleeding postoperatively, one patient had postoperative empyema and three patients had a localised pleural effusion without evidence of infection. There was no mortality.

\section{Recurrent pneumothorax}

Recurrent pneumothorax occurred in 26 patients (1.9\%). Treatment of recurrence was a simple intercostal drain in 9 patients, repeated VATS and talc poudrage in 16 patients and open thoracotomy in 1 patient.

Recurrence was identified in 25 patients due to a recurrence of symptoms and in 1 patient recurrence was identified on a chest radiograph in the absence of symptoms. Recurrence occurred at a median of 13 months (IQR 8-16.5). Thirteen episodes of recurrence occurred in the first year following surgery and 12 episodes in the second year after surgery. The only recurrence later than this occurred at 26 months.

\section{Recurrence according to intervention}

None of the five patients undergoing partial pleurectomy as well as talc poudrage had recurrence. In total, 1003 patients had bullae; of these, 314 patients $(31.3 \%)$ had pleurodesis alone, with the remainder undergoing intervention to their bullae. 
Table 3 Surgical interventions used over study period

\begin{tabular}{lllllllll}
\hline Time period & Poudrage only & Bulla resection & Bulla sutured & Bulla ligation & Electro-coagulation & Lobectomy & Poudrage only (no bullae) & Total \\
\hline $2000-2002$ & 56 & 107 & 66 & 7 & 7 & 2 & 90 & 335 \\
$2003-2005$ & 107 & 45 & 76 & 4 & 8 & 1 & 85 & 31 \\
$2006-2008$ & 85 & 29 & 59 & 5 & 16 & 1 & 286 \\
$2009-2012$ & 66 & 172 & 64 & 5 & 21 & 0 & 140 & 468 \\
\hline
\end{tabular}

A range of targeted surgical interventions were carried out, the details of which are described in table 4.

Recurrence was most common in patients undergoing bullae suturing (3.8\%), electrocoagulation (3.9\%) and ligation (15.0\%). There was no evidence of a statistically significant difference in time to drain removal between surgical intervention groups $(p=0.92)$. There was also no evidence of a statistically significant difference in the incidence of complications between surgical interventions $(p=0.892)$. Surgical intervention did significantly influence length of hospital stay $(p=0.025)$. Hospital stay was shorter in the bulla resection group, but by only 0.2 days $(5 \mathrm{~h})$ compared with the poudrage-only group, and therefore is unlikely to reflect a clinically important reduction.

\section{Influence of patient and surgical factors on risk of recurrence}

The HR of recurrence associated with patient and surgical factors is demonstrated in table 5. Recurrence of pneumothorax was significantly more likely in current smokers compared with non-smokers. The incidence of recurrence in current smokers was 24/575 (4.2\%) and in current non-smokers was 2/805 $(0.2 \%)$. Suturing and ligation of bullae were associated with a significantly increased risk of recurrent pneumothorax compared with patients with bullae who underwent poudrage alone. Electrocoagulation led to a higher incidence of recurrence compared with poudrage alone; however, this difference was not statistically significant.

Figure 2 demonstrates the recurrence of pneumothorax associated with Vanderschueren's stage, intervention to bullae and smoking status. These graphs demonstrate the low incidence of recurrence after 2 years and particularly marked divergence of pneumothorax recurrence curves associated with bullae ligation and current smokers.

\section{DISCUSSION}

This prospectively collected surgical series of 1415 patients undergoing VATS with talc poudrage for PSP is currently the largest published. All patients underwent talc poudrage, and targeted surgical treatment was undertaken in selected patients based on Vanderschueren's stage and the presence of air leak. The study incorporated a robust system to detect recurrence through clinical follow-up, with a follow-up period longer than most other previously published series (median 8.5 years).

The overall cumulative incidence of recurrence in this study was $1.9 \%$. Of note, VATS poudrage alone, either in patients with bullae $(n=307)$ or without bullae $(n=395)$ was associated with a recurrence in only $0.3 \%$ and $1.0 \%$, respectively. Bullae ligation and bullae suturing were associated with a significantly higher incidence of recurrence, $15.0 \%$ and $3.8 \%$, respectively. VATS surgery had a low complication rate of $2.0 \%$. The most common complication was a prolonged air leak, which occurred in $1.7 \%$. There was no surgical mortality.
Despite a long follow-up period (Median 8.5 years), the latest episode of recurrence occurred at 26 months. Recurrent pneumothorax occurred with similar frequency in the first and second year after VATS. The recurrence rate following this 2-year period appears negligible, suggesting that if recurrence is to occur it will do so in the first two postoperative years, with a lack of recurrence at this point strongly suggesting long-term success.

There is a relative lack of published data related to talc poudrage via VATS for PSP. Previous studies have typically used mechanical abrasion to achieve pleurodesis ${ }^{17-20}$ or pleurectomy. ${ }^{15} 21$ Data concerning talc poudrage at thoracoscopy are predominantly from this centre ${ }^{10} 11$ or from studies examining local anaesthetic thoracoscopy. ${ }^{22}$ There are no randomised trials assessing the efficacy of talc poudrage at VATS, though a retrospective analysis of 787 patients with PSP treated with bullectomy and either abrasion or talc poudrage demonstrated a shorter hospital stay and surgical time as well as lower complication rates in the group undergoing talc poudrage compared with the group treated with mechanical abrasion. This study also demonstrated a trend towards a lower incidence of recurrence with poudrage than with abrasion $(p=0.116) .{ }^{23}$ Available data for VATS pleurectomy or mechanical abrasion suggest an incidence of recurrence after these techniques considerably in excess of that reported in our series. The incidence of recurrence following VATS in a large randomised controlled trial in patients with PSP was $14.2 \%$ in the group treated with mechanical abrasion and bullectomy $(n=657){ }^{17}$ The recurrence rate reported by Barker et al of $5.4 \%$ for patients undergoing VATS for PSP overwhelmingly represented patients receiving pleurectomy or mechanical abrasion. ${ }^{6}$

The potential role of VATS after an initial episode of primary pneumothorax is not recommended by guidelines, ${ }^{8}$ though in the future there may be subpopulations for whom its use may be advocated. ${ }^{9}$ A randomised controlled trial comparing local anaesthetic thoracoscopy and talc poudrage with simple chest drain in patients with PSP has demonstrated a cost-saving associated with thoracoscopy. ${ }^{24} \mathrm{~A}$ further recent study of VATS as a first-line therapy in pneumothorax has demonstrated a costsaving and improvement in quality of life compared with patients treated with a chest drain. ${ }^{25}$ These studies have not yet resulted in a change in practice and a widening of the indications for VATS; however, our large cohort providing robust, prospective data on complication and recurrence may add weight to an expansion of the role of definitive treatment earlier in the patient pathway.

The striking difference in incidence of recurrence between current smokers (4.2\%) and non-smokers (0.2\%) suggests that this factor is of key importance in influencing recurrence risk following VATS. Smoking appears an important predictor of recurrent pneumothorax even after VATS with an over 16-fold increased risk of recurrence seen in smokers. This study did not include collection of data on smoking cessation rates, and so it 
Table 4 Incidence of recurrence according to surgical intervention to bullae

\begin{tabular}{|c|c|c|c|c|c|c|c|c|c|}
\hline $\begin{array}{l}\text { Surgical } \\
\text { intervention }\end{array}$ & $\begin{array}{l}\text { Total } \\
\text { no. }\end{array}$ & $\begin{array}{l}\text { Current } \\
\text { smoker } \\
\%\end{array}$ & $\begin{array}{l}\text { Vand. } \\
\text { stage } \\
\text { median } \\
\text { (IQR) }\end{array}$ & $\begin{array}{l}\text { Available } \\
\text { follow-up } \\
\text { data (n) }\end{array}$ & $\begin{array}{l}\text { Cumulative } \\
\text { incidence of } \\
\text { recurrence at } \\
1 \text { year \% (n) }\end{array}$ & $\begin{array}{l}\text { Cumulative } \\
\text { incidence of } \\
\text { recurrence at } \\
2 \text { years \% (n) }\end{array}$ & $\begin{array}{l}\text { Drain } \\
\text { removal by } \\
\text { day } 4, \% \\
\text { (n) }\end{array}$ & $\begin{array}{l}\text { Mean length of } \\
\text { stay (days) }(95 \% \\
\text { CI) }\end{array}$ & $\begin{array}{l}\text { Complications } \\
\% \text { (n) }\end{array}$ \\
\hline $\begin{array}{l}\text { Poudrage only } \\
\text { (bullae present) }\end{array}$ & 314 & 38.2 & $3(3-3)$ & 307 & $0.3(1)$ & $0.3(1)$ & $89.8(282)$ & 5.5 (5.4 to 5.6$)$ & $2.2(7)$ \\
\hline $\begin{array}{l}\text { Bulla resection } \\
\text { (standard stapler) }\end{array}$ & 353 & 45.0 & $3(3-4)$ & 344 & $1.2(4)$ & $1.7(6)$ & 89.5 (316) & 5.3 (5.1 to 5.4$)$ & $1.7(6)$ \\
\hline $\begin{array}{l}\text { Bulla sutured } \\
\text { (no-knife stapler) }\end{array}$ & 265 & 40.0 & $3(3-4)$ & 260 & $2.3(6)$ & $3.8(10)$ & $90.9(241)$ & 5.5 (5.4 to 5.6$)$ & $2.3(6)$ \\
\hline Bulla ligation & 21 & 61.9 & $3(3-3)$ & 20 & $5.0(1)$ & $10.0(2)$ & $95.2(20)$ & $5.6(5.2$ to 5.9$)$ & $0(0)$ \\
\hline Electrocoagulation & 52 & 53.8 & $3(3-3)$ & 51 & $0(0)$ & $3.9(2)$ & $90.4(47)$ & 5.4 (5.2 to 5.6$)$ & $0(0)$ \\
\hline Lobectomy & 4 & 75 & $4(4-4)$ & 3 & $0(0)$ & $0(0)$ & $100(4)$ & 5.5 (4.6 to 6.4$)$ & $0(0)$ \\
\hline $\begin{array}{l}\text { Poudrage only (no } \\
\text { bullae) }\end{array}$ & 406 & 40.1 & $2(2-2)$ & 395 & $0.3(1)$ & $1.0(4)$ & $91.6(372)$ & 5.4 (5.3 to 5.5$)$ & $2.5(10)$ \\
\hline
\end{tabular}

Vand. Stage, Vanderschueren's stage.

is unclear if smoking cessation after surgery will reduce recurrence rates, though there is evidence of a reduction in recurrence of pneumothorax in patients with an initial PSP without surgical treatment and this may be a crucial and modifiable risk factor. $^{26}$

Previous studies assessing the role of local anaesthetic thoracoscopy for pneumothorax have suggested that this is a costeffective intervention for a first spontaneous pneumothorax compared with tube drainage and have demonstrated recurrence in around $5 \% .{ }^{24} 27$ The role of bullae intervention and the extent to which this affects recurrence is a key factor in a comparison between local anaesthetic thoracoscopy and VATS. A more precise understanding of the risks and benefits of the varied bullae interventions may further help drive down the incidence of recurrence after VATS. The results of this study demonstrating a lower incidence of recurrent pneumothorax in patients with bullae undergoing talc poudrage alone $(0.3 \%)$ than those without bullae undergoing talc poudrage (1.0\%) may be supportive of the strategy of undertaking talc poudrage alone in patients with visible bullae and no active air leak at the time of thoracoscopy.

Use of talc as a pleurodesis agent has been limited in patients with pneumothorax, in contrast to its more widespread use in malignant pleural effusion. Historically, concerns have been related to cases of acute respiratory distress syndrome (ARDS) ${ }^{28}$ or the presence of asbestos. The use of large-particle French talc, as used in this study, has been shown to not be associated with ARDS, ${ }^{29}$ an effect thought to be mediated by particle

Table 5 Risk of recurrence according to patient factors and intervention*

\begin{tabular}{|c|c|c|c|c|}
\hline & Recurrence \% (no.) & HR & $95 \% \mathrm{Cl}$ & $\mathrm{p}$ Value \\
\hline \multicolumn{5}{|l|}{ Sex } \\
\hline Female (reference group) & $0.6(2 / 329)$ & 1.00 & & \\
\hline Male & $2.3(24 / 1051)$ & 2.91 & 0.67 to 12.65 & 0.15 \\
\hline \multicolumn{5}{|l|}{ Current smoking status } \\
\hline Non-smoker (reference) & $0.2(2 / 805)$ & 1.00 & & \\
\hline Smoker & $4.2(24 / 575)$ & 15.18 & 3.55 to 64.75 & $<0.001$ \\
\hline \multicolumn{5}{|l|}{ Bulla intervention } \\
\hline Poudrage only (reference) & $0.3(1 / 307)$ & 1.00 & & - \\
\hline Bulla resection (standard stapler) & $1.7(6 / 344)$ & 4.14 & 0.47 to 36.11 & 0.20 \\
\hline Bulla sutured (no knife stapler) & $3.8(10 / 260)$ & 9.38 & 1.16 to 76.04 & 0.036 \\
\hline Bulla ligation & $15.0(3 / 20)$ & 26.68 & 2.75 to 258.57 & 0.005 \\
\hline Electrocoagulation & $3.9(2 / 51)$ & 9.51 & 0.86 to 105.53 & 0.067 \\
\hline Lobectomy & $0.0(0 / 3)$ & n/at & $\mathrm{n} / \mathrm{a}$ & - \\
\hline No Bullae & $1.0(4 / 395)$ & 5.51 & 0.02 to 1415.94 & 0.55 \\
\hline \multicolumn{5}{|l|}{ Vanderschueren's stage } \\
\hline 1 & $3.4(1 / 29)$ & 9.17 & 0.81 to 103.73 & 0.073 \\
\hline 2 (reference) & $0.8(3 / 372)$ & 1.00 & & \\
\hline 3 & $1.8(14 / 785)$ & 2.11 & 0.01 to 392.16 & 0.78 \\
\hline 4 & $4.1(8 / 194)$ & 3.47 & 0.02 to 678.70 & 0.64 \\
\hline \multicolumn{5}{|l|}{ Side } \\
\hline Right (reference) & $1.7(14 / 826)$ & 1.00 & & \\
\hline Left & $2.2(12 / 554)$ & 1.47 & 0.68 to 3.21 & 0.33 \\
\hline
\end{tabular}


A Pneumothorax Recurrence by Vanderschueren's Stage

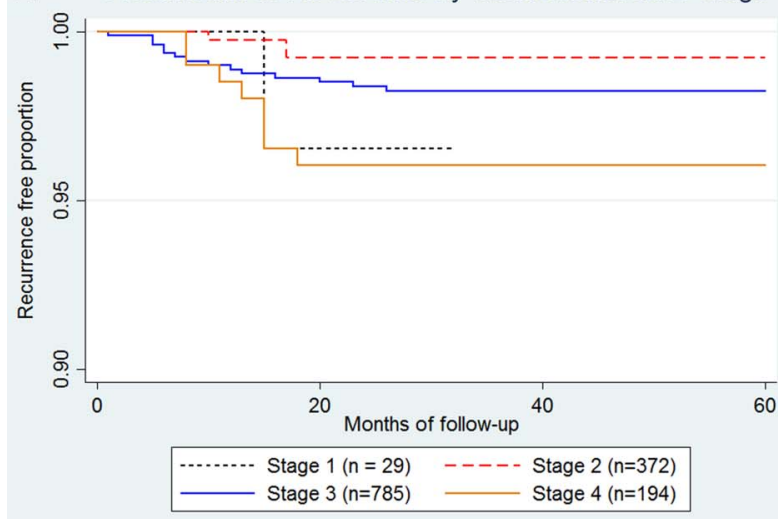

B Pneumothorax Recurrence by Bulla Intervention

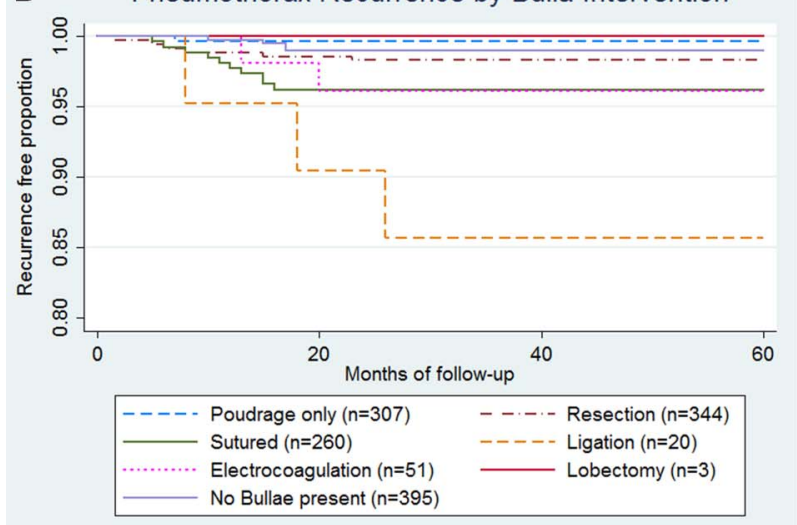

C Pneumothorax Recurrence by Smoking Status

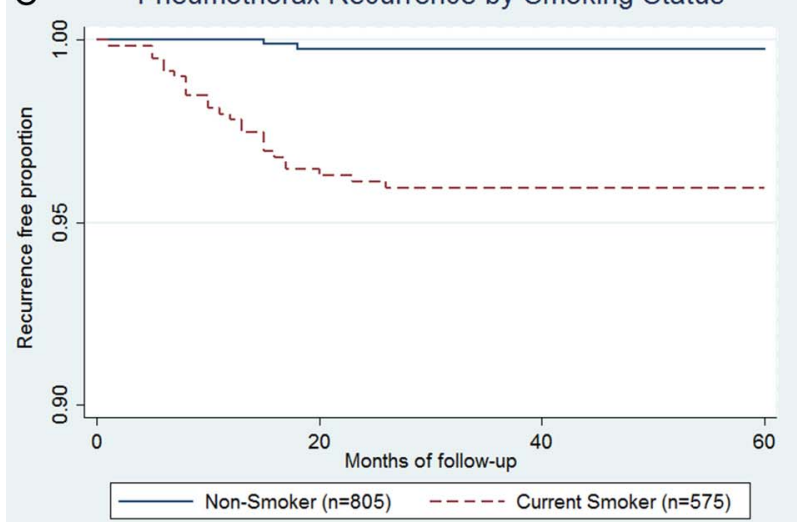

Figure 2 Kaplan-Meier curves showing pneumothorax recurrence in 1380 patients by (A) Vanderschueren's stage (B) bulla intervention and (C) smoking status.

size. ${ }^{30}$ Reassuringly, lung function measures 5 years after VATS with talc poudrage show no significant deterioration compared with control patients with pneumothorax not undergoing poudrage. ${ }^{31}$ Additionally, follow-up data up to 35 years after talc poudrage for pneumothorax are reassuring with respect to its long-term safety. ${ }^{32-34}$ Concern has previously been expressed regarding the ease with which VATS could be undertaken subsequent to talc pleurodesis, ${ }^{12}$ and though re-VATS is feasible in this population after talc poudrage it is described as being more demanding than following mechanical abrasion and there is a considerable rate of conversion to thoracotomy. ${ }^{35} 36$

This study represents a large cohort of patients from a single centre of expertise, and results may not reflect those seen in other centres. As this study is observational, no clear conclusions can be drawn regarding the relative effect of different interventions on recurrence. Surgical procedures were performed on the basis of Vanderschueren's stage, the presence or absence of air leak and variations in practice among surgeons, some of which may have changed over the study period. As a result of this, comparison between surgical groups is limited by confounding variables. As patients undergoing talc poudrage alone universally had no air leak seen at a water test, no firm comparisons can be made between this cohort and the cohort of patients with air leak undergoing targeted surgical treatments and the multivariable analysis should therefore be interpreted with caution. Randomised controlled trial data are required to establish whether talc poudrage is superior to mechanical pleurodesis or pleurectomy for treatment of PSP and whether the efficacy of VATS poudrage in patients with bullous disease, without an active air leak, is improved by the addition of direct surgical intervention to bullae.

In conclusion, this study of 1415 patients has established a low incidence of pneumothorax recurrence $(1.9 \%)$ in patients undergoing VATS with talc poudrage. This is considerably lower than the incidence of recurrence reported in studies using VATS with pleurectomy or mechanical abrasion. Complications occurred in $2.0 \%$, though the vast majority of these were prolonged air leak following surgery and there was no mortality. Bullae suturing and bullae ligation were associated with a significantly higher incidence of recurrence compared with patients undergoing talc poudrage alone even when controlled for smoking status and Vanderschueren's stage. Current smoking status at the time of surgery is strongly associated with recurrent pneumothorax after VATS. This study is the largest prospective study of VATS for PSP and demonstrates VATS with talc poudrage in this population is a highly efficacious and safe procedure.

Contributors GC and OJB contributed equally to the paper. GC, FC, LC and MDM performed thoracic surgery and performed data collection. OJB performed the analysis and produced the draft manuscript. BCK provided statistical expertise and wrote the statistical methodology. NAM assisted in the writing, editing and analysis of the manuscript. All authors have reviewed and approved the final manuscript.

Competing interests None declared.

Ethics approval The Institutional Review Board of Carlo Forlanini Hospital. Provenance and peer review Not commissioned; externally peer reviewed. Data sharing statement Raw unpublished data are available on request.

\section{REFERENCES}

1 Foroulis CN, Anastasiadis K, Charokopos N, et al. A modified two-port thoracoscopic technique versus axillary minithoracotomy for the treatment of recurrent spontaneous pneumothorax: a prospective randomized study. Surg Endosc 2012;26:607-14.

2 Chen JS, Chan WK, Tsai KT, et al. Simple aspiration and drainage and intrapleural minocycline pleurodesis versus simple aspiration and drainage for the initial treatment of primary spontaneous pneumothorax: an open-label, parallel-group, prospective, randomised, controlled trial. Lancet 2013;381:1277-82.

3 Noppen $\mathrm{M}$, Alexander $\mathrm{P}$, Driesen $\mathrm{P}$, et al. Manual aspiration versus chest tube drainage in first episodes of primary spontaneous pneumothorax: a multicenter, prospective, randomized pilot study. Am J Respir Crit Care Med 2002;165:1240-4.

4 Sedrakyan A, van der Meulen J, Lewsey J, et al. Video assisted thoracic surgery for treatment of pneumothorax and lung resections: systematic review of randomised clinical trials. BMJ 2004;329:1008.

5 The Thoracic Surgery Registry Brief Report Audit Years 2011-12 to 2013-14: Society for Cardiothoracic Surgery in Great Britain and Ireland, 2015.

6 Barker A, Maratos EC, Edmonds L, et al. Recurrence rates of video-assisted thoracoscopic versus open surgery in the prevention of recurrent pneumothoraces: a systematic review of randomised and non-randomised trials. Lancet 2007:370:329-35.

7 Waller DA. Video-assisted thoracoscopic surgery for spontaneous pneumothorax-a 7-year learning experience. Ann R Coll Surg Engl 1999;81:387-92. 
8 MacDuff A, Arnold A, Harvey J, et al. Management of spontaneous pneumothorax: British Thoracic Society Pleural Disease Guideline 2010. Thorax 2010;65(Suppl 2): ii 18-31.

9 Bintcliffe OJ, Hallifax RJ, Edey A, et al. Spontaneous pneumothorax: time to rethink management? Lancet Respir Med 2015;3:578-88.

10 Cardillo G, Facciolo F, Giunti R, et al. Videothoracoscopic treatment of primary spontaneous pneumothorax: a 6 -year experience. Ann Thorac Surg 2000;69:357-61; discussion 361-2.

11 Cardillo G, Carleo F, Giunti R, et al. Videothoracoscopic talc poudrage in primary spontaneous pneumothorax: a single-institution experience in 861 cases. J Thorac Cardiovasc Surg 2006;131:322-8.

12 Tschopp JM, Bintcliffe O, Astoul P, et al. ERS task force statement: diagnosis and treatment of primary spontaneous pneumothorax. Eur Respir J 2015;46:321-35

13 Noppen M, Dekeukeleire T, Hanon S, et al. Fluorescein-enhanced autofluorescence thoracoscopy in patients with primary spontaneous pneumothorax and normal subjects. Am J Respir Crit Care Med 2006;174:26-30.

14 Horio $H$, Nomori $H$, Kobayashi R, et al. Impact of additional pleurodesis in video-assisted thoracoscopic bullectomy for primary spontaneous pneumothorax. Surg Endosc 2002;16:630-4.

15 Hatz RA, Kaps MF, Meimarakis G, et al. Long-term results after video-assisted thoracoscopic surgery for first-time and recurrent spontaneous pneumothorax. Ann Thorac Surg 2000;70:253-7.

16 Loubani M, Lynch V. Video assisted thoracoscopic bullectomy and acromycin pleurodesis: an effective treatment for spontaneous pneumothorax. Respir Med 2000;94:888-90.

17 Lee $\mathrm{S}, \mathrm{Kim}$ HR, Cho S, et al. Staple line coverage after bullectomy for primary spontaneous pneumothorax: a randomized trial. Ann Thorac Surg 2014;98:2005-11.

18 Gossot D, Galetta D, Stern JB, et al. Results of thoracoscopic pleural abrasion for primary spontaneous pneumothorax. Surg Endosc 2004;18:466-71.

19 Freixinet JL, Canalís E, Juliá G, et al. Axillary thoracotomy versus videothoracoscopy for the treatment of primary spontaneous pneumothorax. Ann Thorac Surg 2004;78:417-20.

20 Chan P, Clarke P, Daniel FJ, et al. Efficacy study of video-assisted thoracoscopic surgery pleurodesis for spontaneous pneumothorax. Ann Thorac Surg 2001;71:452-4.

21 Inderbitzi RG, Leiser A, Furrer $M$, et al. Three years' experience in video-assisted thoracic surgery (VATS) for spontaneous pneumothorax. J Thorac Cardiovasc Surg 1994;107:1410-15.
22 Györik S, Erni S, Studler U, et al. Long-term follow-up of thoracoscopic talc pleurodesis for primary spontaneous pneumothorax. Eur Respir J 2007;29:757-60.

23 Moreno-Merino S, Congregado M, Gallardo G, et al. Comparative study of talc poudrage versus pleural abrasion for the treatment of primary spontaneous pneumothorax. Interact Cardiovasc Thorac Surg 2012;15:81-5.

24 Tschopp JM, Boutin C, Astoul P, et al. Talcage by medical thoracoscopy for primary spontaneous pneumothorax is more cost-effective than drainage: a randomised study. Eur Respir J 2002;20:1003-9.

25 Divisi D, Di Leonardo G, Crisci R. Video-assisted thoracic surgery versus pleural drainage in the management of the first episode of primary spontaneous pneumothorax. Am J Surg 2015;210:68-73.

26 Sadikot RT, Greene T, Meadows K, et al. Recurrence of primary spontaneous pneumothorax. Thorax 1997;52:805-9.

27 Tschopp JM, Brutsche M, Frey JG. Treatment of complicated spontaneous pneumothorax by simple talc pleurodesis under thoracoscopy and local anaesthesia. Thorax 1997;52:329-32.

28 Rehse DH, Aye RW, Florence MG. Respiratory failure following talc pleurodesis. Am J Surg 1999;177:437-40.

29 Janssen JP, Collier G, Astoul P, et al. Safety of pleurodesis with talc poudrage in malignant pleural effusion: a prospective cohort study. Lancet 2007;369:1535-9.

30 Maskell NA, Lee YC, Gleeson FV, et al. Randomized trials describing lung inflammation after pleurodesis with talc of varying particle size. Am J Respir Crit Care Med 2004;170:377-82.

31 Cardillo G, Carleo F, Carbone L, et al. Long-term lung function following videothoracoscopic talc poudrage for primary spontaneous recurrent pneumothorax. Eur J Cardiothorac Surg 2007;31:802-5.

32 Lange $\mathrm{P}$, Mortensen J, Groth S. Lung function 22-35 years after treatment of idiopathic spontaneous pneumothorax with talc poudrage or simple drainage. Thorax 1988;43:559-61.

33 Viskum K, Lange $P$, Mortensen J. Long term sequelae after talc pleurodesis for spontaneous pneumothorax. Pneumologie 1989;43:105-6.

34 Hunt I, Barber B, Southon $R$, et al. Is talc pleurodesis safe for young patients following primary spontaneous pneumothorax? Interact Cardiovasc Thorac Surg 2007;6:117-20.

35 Cardillo G, Facciolo F, Regal M, et al. Recurrences following videothoracoscopic treatment of primary spontaneous pneumothorax: the role of redo-videothoracoscopy. Eur J Cardiothorac Surg 2001;19:396-9.

36 Doddoli C, Barlési F, Fraticelli A, et al. Video-assisted thoracoscopic management of recurrent primary spontaneous pneumothorax after prior talc pleurodesis: a feasible, safe and efficient treatment option. Eur J Cardiothorac Surg 2004;26:889-92. 